\title{
Death of a child due to dog bites - a bite mark analysis
}

SADJ March 2020, Vol. 75 No. 2 p79 - p80

VM Phillips

\section{CASE REPORT}

I was requested by Dr DA of the Department of Forensic Pathology in Paarl Western Cape, to examine bite marks inflicted by dogs on a deceased child at Paarl Forensic Pathology Laboratory. The deceased was a male child of approximately 7 years of age who was attacked by a male and a female Pit Bull Terrier.

It was alleged that these dogs leapt over the wall and attacked the child outside the property of the owner. Examination of the victim showed numerous lacerations and deep puncture wounds on the neck, arms, legs, back and buttocks.

Photographs were taken of the entire body of the victim to record the anatomical location of the lesions. Some of the lesions were scratch marks from the claws of the dogs. The puncture wounds were due to the dog teeth. Several puncture wounds had deep lacerations and were not suitable for bite mark analysis. Photographs were taken of the puncture wound that represented dog bite marks.

The puncture wound on the right shoulder of the victim was considered to be the best example of a dog bite and was photographed with an ABFO millimetre scale in situ (Fig. 1).

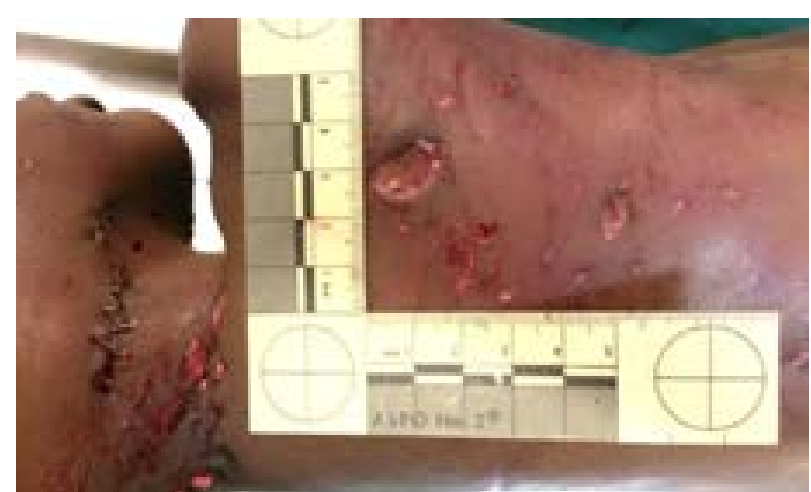

Figure 1. The puncture wound on the right shoulder of the victim with the ABFO $\mathrm{mm}$ scale in situ. Several smaller puncture wounds are present in this area.

\section{Author affiliations:}

1. Vincent M Phillips: BDS, MChD, Dip Max-Facial Radiol, FC Path SA (Oral Path), PhD, DSc, Emeritus Professor, Department Oral and Maxillo-Facial Pathology and Forensic Science, Faculty of Health Sciences, University of the Western Cape. ORCID Number: 0000-0003-1432-6274

Corresponding author: Vincent M Phillips

Department Oral and Maxillo-Facial Pathology and Forensic Science.

Faculty of Health Sciences, University of the Western Cape.

Email: vmphillips@uwc.ac.za

\section{ACRONYM \\ ABFO: $\quad$ American Board of Forensic Odontology}

Two deceased adult dogs, a male and a female Pit Bull Terrier, were presented for examination of their teeth and possible matching with the bite marks on the victim. Photographs were taken of the front teeth of the male dog and then dental impressions were taken of the upper and lower front teeth.

The female dog was frozen and had to be defrosted overnight before the mouth could be opened for examination. The dentition of the female dog was examined the following day and photographed. Dental impressions were taken of the upper and lower front teeth of this dog. Plaster of Paris study models were cast from the dental impressions of the upper and lower teeth of each dog for bite mark analysis (Figs. 3 \& 4).

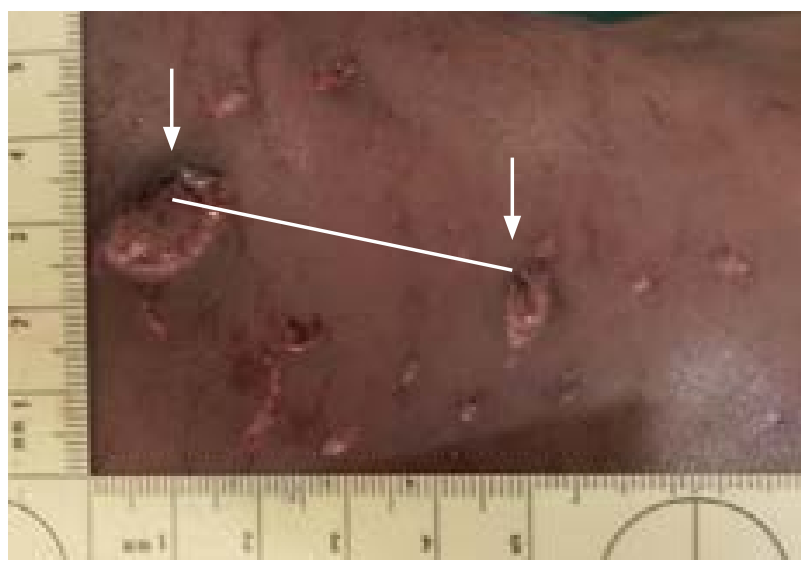

Figure 2. Deep puncture wound on the left shoulder of the victim due to the dog bite. The deep puncture wounds are due to the canine teeth (arrows). The wounds show tearing of the tissues. The other lesions are due to the dog's incisor teeth. The distance between the deep puncture wounds is $45 \mathrm{~mm}$ (white line) ABFO $\mathrm{mm}$ scale in situ.

\section{Bite mark analysis}

The analysis of a human bite mark is undertaken by matching the biting patterns of the upper and lower teeth of the perpetrator with the bite mark. A tracing of the biting pattern is superimposed over a photograph of the bite mark. This bite mark by a dog was a unique experience for the author.

The most distinctive bite mark for analysis was situated on the right shoulder of the victim (Fig. 1). The two deep puncture wounds were produced by the canine teeth of the dog. The distance between the centres of each puncture wound was $45 \mathrm{~mm}$ (Fig. 2). 

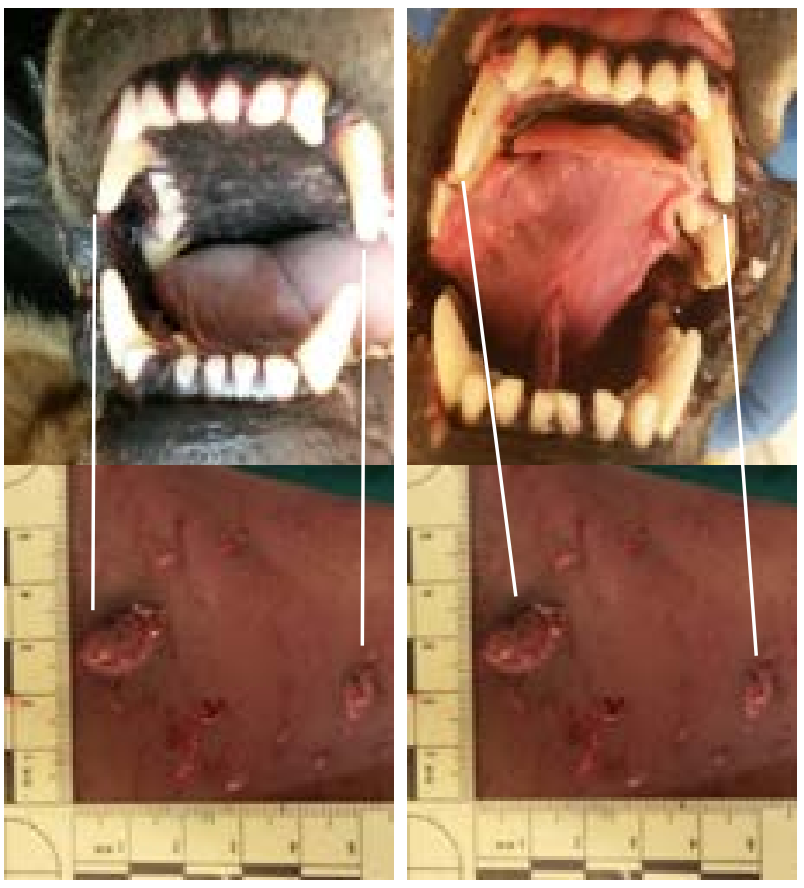

Figure 3. The relationship between the upper canine teeth of the male (left) and female (right) dog with the puncture wounds showed the inter-canine distance in both dogs was $45 \mathrm{~mm}$.

\section{DISCUSSION}

The puncture wounds showed distortion due to tearing of the tissues; thus showing a discrepancy in the sizes of the left and right puncture wounds.

The distance between the centres of the puncture wounds was found to be $45 \mathrm{~mm}$ (Fig. 2). The intercanine distance in both dogs was measured at $45 \mathrm{~mm}$. This was surprizing as the male dog is usually more robust than the female.

The taking of the dental impressions of the dog's teeth was challenging because the standard dental impression tray does not compensate for long canines. The impression trays had to be modified.

In retrospect it was unnecessary to take dental impressions as the inter-canine distances could have been measured in situ for each dog. No distinct biting pattern for the incisor teeth was discernible as these teeth are much smaller than the canines (Figs. 2 \& 3).

Bite marks due to dogs result in deep puncture wounds due to the canine teeth with possible minor wounds due to the adjacent incisor teeth. The wounds inflicted by dog bites may be distorted due to the tearing of the tissues as a result of the shaking of the head of the dog while inflicting the bite. The numerous deep scratch marks by the claws of the dogs caused masking of some of the bites and complicated the analysis.

\section{CONCLUSION}

Numerous bite marks and lacerations were present on the body of the victim. The lesion on the right shoulder of the victim was determined to have been caused by a dog bite.
Comparison between the upper canine teeth of the male and female dogs presented for examination showed that either of these dogs could have inflicted the bite on the right shoulder of the child.

\section{Declaration}

No conflict of interest is declared.

\section{References}

1. Kashyap B, Anand S, Reddy S, Sahukar S B, Supriya N, Pasupuleti $\mathrm{S}$. Comparison of the bite mark pattern and intercanine measurement between humans and dogs. Journal of Forensic Dental Sciences. 2015; 7(3): 175-8.

2. Thompson IOC, Phillips VM. Bite mark case with a twist. The Journal of Forensic Odonto-stomatology, 1994; 12: 37-40.

3. Maistry S, Phillips VM. Forensic dentistry case book 6: A self-inflicted bite mark; a case report. SADJ. March 2016; 71(2): 76-7.

4. Mohamed N, Phillips VM. Accuracy of acetate overlays in bite mark comparison: How accurate is an ideal bite pattern? SADJ November 2017; 72(10): 456 - 61

5. Phillips VM, Avelino D. Bite mark analysis in a case of child abuse. SADJ. September 2019; 74(8): 451-3. 